\title{
The Distribution and Function of Aquaporin 1 and 2 Along the Kidney in Different Species
}

\author{
Distribución y Función de la Acuaporina 1 y 2 a lo Largo del Riñón en Diferentes Especies
}

\author{
Fengli An ${ }^{1} \&$ Shun $\mathrm{Zhu}^{2}$
}

AN, F. \& ZHU, S. The distribution and function of aquaporin 1 and 2 along the kidney in different species. Int. J. Morphol., 39(3):890$895,2021$.

SUMMARY: Water metabolism in kidney is critical for organisms living in arid environments. In this study, the kidney structure and the expression of AQP1 and AQP2 in Phrynocephalus vlangalii and Camelus bactrianus were studied. It was found that the Phrynocephalus vlangalii has fewer renal corpuscle but developed kidney tubules, and AQP1 and AQP2 were mainly expressed in the kidney tubules. Camelus bactrianus has a large diameter of glomerulus, thick bulbar membrane, and long and dense urinary tract. AQP1 was highly expressed in the proximal convoluted tubule, proximal straight tubule, and Ansa nephroni (Henle's loop), and AQP2 was also highly expressed in the collecting tubule and distal convoluted tubule. In the long-term evolutionary adaptation, the morphological structure of animal kidney is consistent with its environment. In addition to structural and functional adaptation, aquaporin also participates in the adaptation to water scarcity environment, and may also play a key role.

KEY WORDS: Aquaporin1; Aquaporin2; Kidney; Phrynocephalus vlangalii; Camelus bactrianus.

\section{INTRODUCTION}

Vigorous metabolism in terrestrial animals is accompanied by multitudinous metabolite especially nitrogen-containing component which lead to a burden on the body. So, it is necessary to mobilize a lot of water to dissolve them and get them out of the body, but that is in contradiction with the water conservation mechanism in terrestrial life. Phrynocephalus vlangalii and Camelus bactrianus are special species in our country (Jin \& Liu, 2007.; The Bactrian Camels Genome Sequencing and Analysis Consortium, 2012) and playing vital roles in ecosystem balance. They usually survive in severe drought areas, so fluid secretion or absorption are prerequisite for them when confronting water shortage. Evolutionary adaptation causing the kidney to produce a series of adaptive response such as the relatively large proportion of the renal medulla, the higher renal structure index and so on (Mbassa et al., 1988).

However, structure adaptation of kidney to maintain water and electrolyte body fluid composition is within a very narrow range. There are other mechanisms such as Aquaporins (AQPs) mediating water transportation outside of this range. AQPs are proteins that allow the transcellular water transportation driven by osmotic forces. In the absence of AQPs, diffusional permeability is low in lipid bilayers when exposed to an osmotic gradient. AQPs are classified into essentially permeable to water, permeable to water but also to glycerol, urea, and small solutes and unorthodox AQPs with highly variable NPA motifs (Ishibashi et al., 2014). There are 13 isoforms have so far been reported in human tissue and at least 8 are known to be present in the kidney. AQP1 is a water-channel protein and the expression of AQP1 is associated to hypertonicity and AQP1-knockout mice exhibited grossly normal phenotypes (Seyahian, et al., 2020). AQP1 null mice are mildly growth-retarded, manifest a severe urinary concentrating defect and have reduced water permeability between airspace and capillary compartments (Lanaspa et al., 2010). AQP1 in descending vasa recta, together with AQP1 in descending thin limbs, plays a fundamental role in establishing and maintaining the axial osmolality gradient through countercurrent multiplication (Westrick et al., 2012). Genetically modified mice lacking AQP2 in the collecting duct but expressing it in connecting tubules suffer from severe urinary concentration defect, and

\footnotetext{
${ }^{1}$ School of Pharmacy, Lanzhou university, Gansu, China.

${ }^{2}$ Suzhou Hua Jian Rui Da Pharmaceutical Technology Co., LTD, Jiangsu, China.
} 
those globally lacking AQP2 die within 2 weeks due to growth retardation (Kortenoeven et al., 2013). Furthermore, AQP2 has been linked to numerous conditions with disturbed water balance and AQP2 is involved in chronic/adaptational control of body water balance, which is achieved through regulation of AQP2 expression (Nielsen et al., 2007). The long-term alteration in concentrating capacity is presumed to be due to an increase in total AQP2 caused by a change in gene transcription (Nielsen et al., 2002). These results all suggest that there are no other good mechanisms compensating for AQPs.

Of all regions in the body, environmental osmolality is by far the highest in the kidney and this is a greater challenge for animals living in arid and water-scarce environments. Novel quantitative fluorescence methods demonstrated very high water permeabilities of the alveolar epithelial and endothelial barriers, and moderately high water permeability across distal airways. Although a great deal of filtered fluid is reabsorbed in the kidney which is essential for appropriate animal organ function, but the mechanism strategies confronting water shortage for them is unknow. Therefore, the present study was carried out to investigate the distribution of AQP1?AQP2 in kidney of Phrynocephalus vlangalii and Camelus bactrianus, which may provide not only morphological structure but also histochemistry data for water transportation in animals how to deal with water shortage.

\section{MATERIAL AND METHOD}

Animals and tissues preparation. The present study was carried out on Phrynocephalus vlangalii whose body length were aboved 50mm and Camelus bactrianus who aged 5-6 years. Animals were randomly selected during September to November from GeErMu, QingHai Province, China. Samples obtained from animals were fixed with $4 \%$ paraformaldehyde for no less than $24 \mathrm{~h}$, then the tissues were thoroughly washed in PBS, dehydrated in graded ethanol and embedded in paraffin. Five micrometer-thick sections were cut from each tissue.

Immunohistochemistry. Tissue sections were deparaffinized in xylene, washed in alcohol and rehydrated in PBS. Antigen retrieval was performed in a microwave oven in $0.01 \mathrm{M}$ PBS ( $\mathrm{pH} 7.4$ ) for $15 \mathrm{~min}$, then the sections were cooled at room temperature and washed again in PBS. Endogenous peroxidase was blocked by using $3 \%$ hydrogen peroxide for $30 \mathrm{~min}$. After washing in PBS for three times, the goat serum $(10 \%)$ was used for 20 min to avoid any non-specific reactions. Then, the primary antibody, polyclonal rabbit anti-AQP1, AQP2 were applied (sigma, dilution 1:500) and incubated in a moist chamber at 4 ? overnight. Sections were incubated with biotin-labelled secondary antibodies and avidin-HRP third antibodies, positive staining was detected using DAB. The sections were counterstained with hematoxylin. Negative control sections have the same procedure except omitting primary antibody.

Analysis. A light microscopy was utilized for the histology studies of the sections (Zeiss, Germany), and photomicrographs were recorded with a digital camera (Germany).

\section{RESULTS}

General renal anatomy of Phrynocephalus vlangalii and Camelus bactrianus. The kidney of Phrynocephalus vlangalii are located in the posterior part of the body and as flat elliptical solid organ. It is composed of fibrous capsule, capillary and uriniferous tubule (Fig. 1.A). The fibrous capsule is a thin layer of dense connective tissue, which is wrapped in the lateral part of the kidney and extends to the interior with the interlobular space to form interlobular connective tissue (Fig. 1.B). The thin capillary endothelial cells are in contact with the mesangium (Fig. 1.C). Bowman's capsule is composed of visceral and parietal layers (Fig. 1.D). The podocytes of the glomerular connected to capillaries (Fig. 1.E). There was no significant cortical or medullary division in the parenchyma, but a small number of renal corpuscles in the superficial cortex and well developed renal tubules in medulla (Fig. 1.F).

The kidney of Camelus bactrianus belongs to the single nipple kidney with smooth surface and as bean shape. It was divided into medulla (Fig. 1.G-I) and cortex (Fig. 1.JL). The renal corpuscles were mainly located in cortical(Fig. 1.J) and had different diameters. The glomeruli are mostly round or oval, surrounded by a large number of renal tubules, including proximal tubules, fine segments and distal tubules (Fig. 1.J-L). The superficial cortical renal corpuscles are obviously smaller than the deep layer, the collecting tube gradually increases from the cortex to the medulla, the height of the epithelium has no obvious change, the medulla contains abundant apolipid interstitial cells, and the matrix contains acidic mucus (Fig. 1.L). The basal membrane of the vascular bulb of bactrian camel is very thick, and the podocytes have narrow and few pores between the ends of the adjacent podocytes.

Immunohistochemical examination of AQP1 in the kidney from Phrynocephalus vlangalii and Camelus 

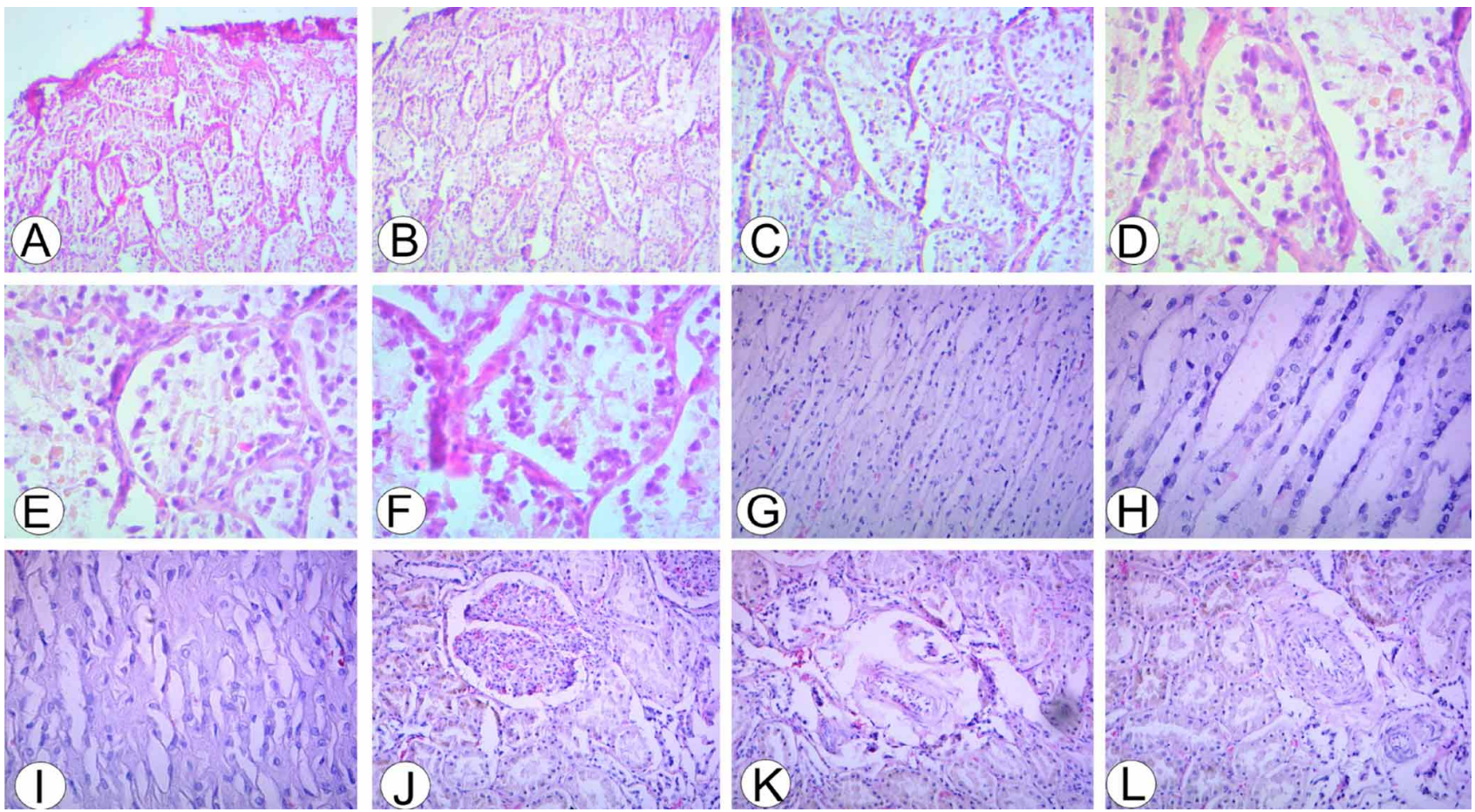

Fig.1. Microstructure of the kidney from Phrynocephalus vlangalii (A-F) and Camelus bactrianus(G-L). A-L shows: glomerulus; Bowman's capsule (BC); proximal straight tubule (PR); proximal convoluted tubule (PCT); distal tubule (Dt); cortical collecting duct (CCD); thin limb of Ansa nephroni (Henle's loop), outer medullary collecting duct (OMCD); inner medullary collecting duct (IMCD).

bactrianus. In the kidney of Phrynocephalus vlangalii, AQP1 is extremely abundant in the proximal tubule (Fig. 2.B) and descending thin limb (Fig. 2.C)where it appears to be the main site for proximal nephron water reabsorption. It is also present in the descending vasa recta (Fig. 2.D). The mesangium which is composed mostly of irregular satellite cells also has AQP1 expression in the epithelial basement membrane and the capillary endothelium (Fig. 2.A).
In the kidney of Camelus bactrianus, there was no positive reactions of AQP1 in the corpuscle (Fig. 2.F) but strong positive reactions of AQP1 in the proximal straight tubule (Fig. 2.G), proximal convoluted tubule (Fig. 2.H) and thin limb of Ansa nephroni (Henle's loop) (Fig. 2.I). The positive substance is mainly expressed in the cytoplasm and cell membrane of the wall epithelial cells. The positive intensity on the top and side membranes was stronger than that on the other sites.
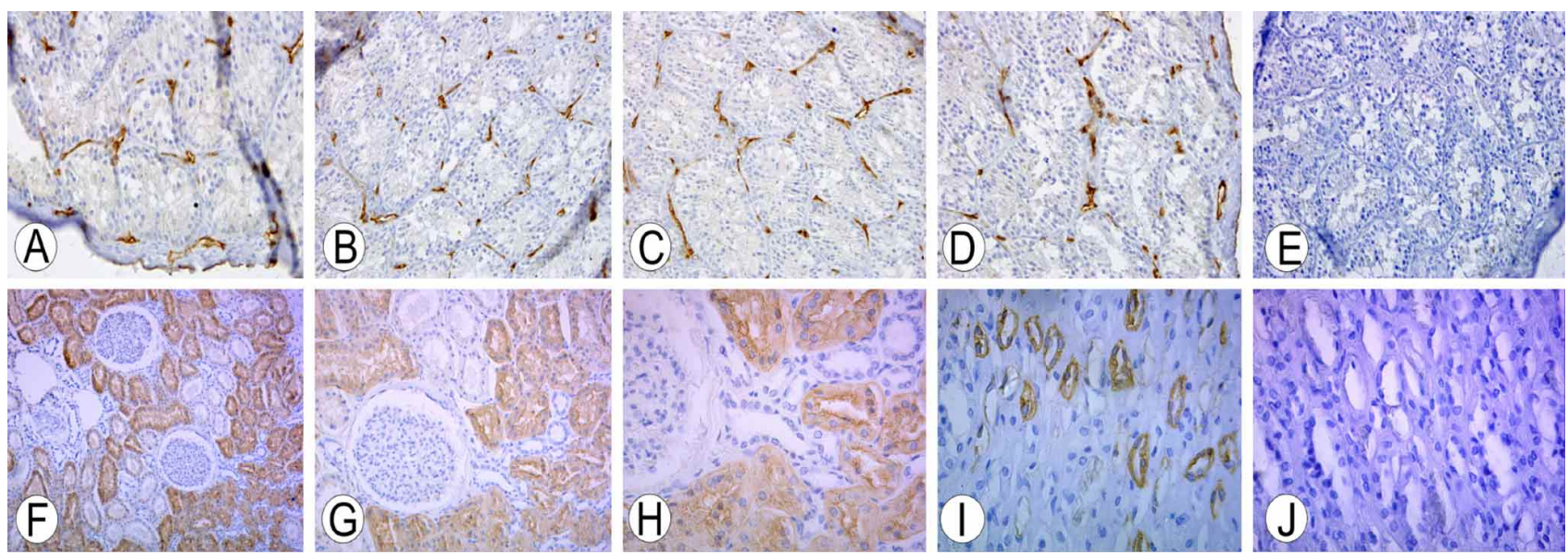

Fig. 2. Immunohistochemistry of AQP1 in kidney from Phrynocephalus vlangalii (A-E) and Camelus bactrianus (F-J). AQP1 reacted strongly with the cells in the mucous and capillary endothelium cells (A), proximal tubule (B), descending thin limb (C) and vasa recta (D); Strong positive reactions of AQP1 in the proximal straight tubule (F,G), proximal convoluted tubule (H) and thin limb of Ansa nephroni (Henle's loop) (I); Negative control was performed in the absence of primary antibody (E, J). 
Immunohistochemical examination of AQP2 in the kidney from Phrynocephalus vlangalii and Camelus bactrianus. In the kidney of Phrynocephalus vlangalii, there was no positive reactions of AQP1 in the corpuscle (Fig. 3.A). In loose connective tissue, there are AQP2 expression (Fig. 3.B). AQP2 is extremely abundant in the proximal tubule and descending thin limb (Fig. 3.C) where it appears to be the main site for proximal nephron water reabsorption.
In the kidney of Camelus bactrianus, AQP2 showed strong expression in the apical plasma membrane and intracellular vesicles of principal cells in the outer medullary collecting duct (Fig. 3.E) and inner medullary collecting duct (Fig. 3.F). There was no AQP2 protein positive reaction in renal corpuscles, but strong positive reaction in thin limb of Ansa nephroni (Henle's loop) (Fig. 3.G). The positive substance was found in the cytoplasm and apical membrane of epithelial cells.
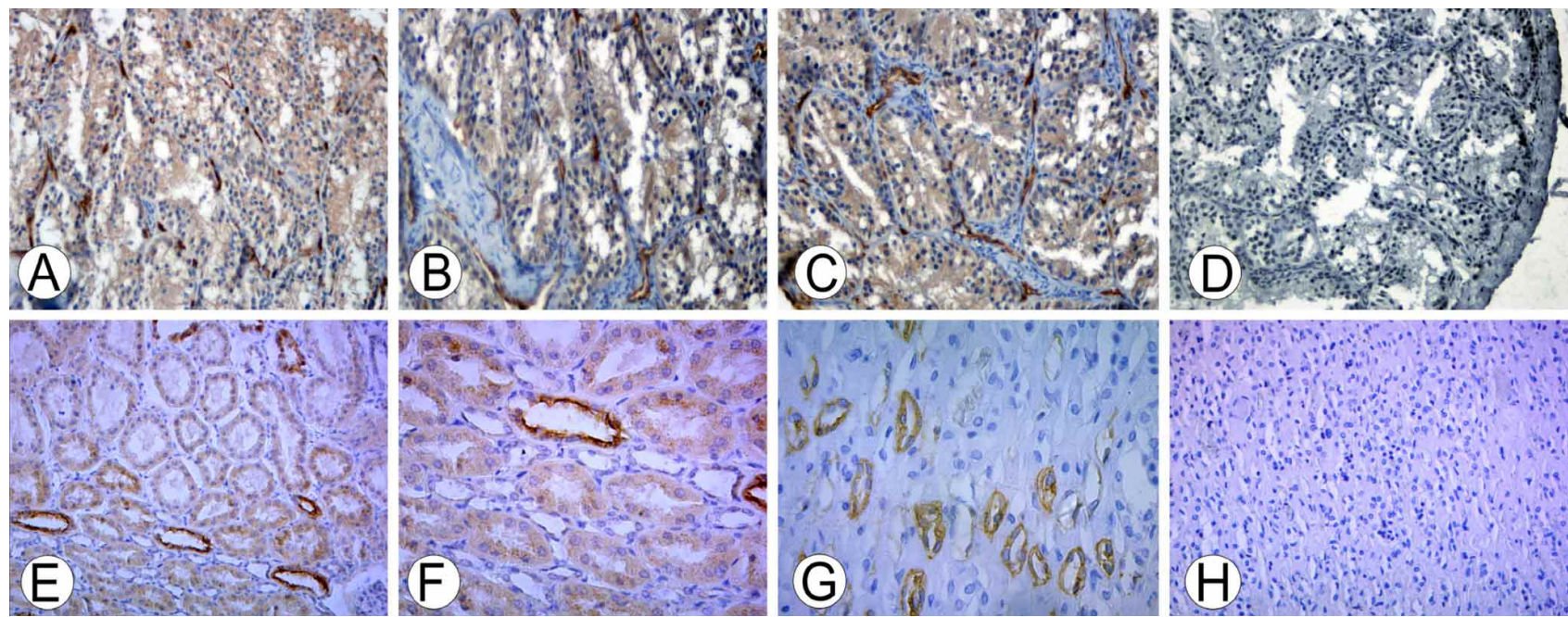

Fig.3. Immunohistochemistry of AQP2 in kidney from Phrynocephalus vlangalii (A-D) and Camelus bactrianus (E-H). AQP2 expression in endothelial cells (A), loose connective tissue (B), in the proximal tubule and descending thin limb (C); AQP2 reacted strongly with the cells in the outer medullary collecting duct and inner medullary collecting duct (E, F); AQP2 was expressed in thin limb of Ansa nephroni (Henle's loop) $(\mathrm{G})$; Negative control was performed in the absence of primary antibody $(\mathrm{D}, \mathrm{H})$.

\section{DISCUSSION}

Water, temperature, humidity and so on are the limiting factors for animal survival. In the long-term evolutionary adaptation, morphological structure of the organ is consistent with its environment (Romagnani et al., 2013). Kidney is sensitive to the water supply, so it is a good experimental material to study the response of water stress in animals. At the same time, exploring the evolution of kidney under external environmental intervention is important for understanding its function. Primitive vertebrates live in the same saline environment as the autogenous extracellular fluid, so these organisms are free to ingest the surrounding seawater without affecting the composition of the environment (Romagnani et al.). Reptilian first appeared metanephridium, but no obvious cortical and medullary division of the kidney has evolved (Solomon et al., 1985). Physical differences lead to distinction in kidney morphology between the two species, but the basic structure of the kidneythe renal units are similar and conserved. Phrynocephalus vlangalii has a functional meta nephridium, including renal corpuscles, proximal tubules, distal tubules and collecting tubules. Due to lower metabolic level and little metabolites, there are not so many renal corpuscles. Uric acid, which is insoluble in water in raw urine, is excreted with feces. But well developed renal tubules in Phrynocephalus vlangalii have strong water absorption ability which can keep water in life. The renal capsule of Camelus bactrianus is thicker, and there is a large astral vein under the capsule, which is mainly composed of dense collagen fibers. The superficial cortical renal corpuscles are obviously smaller than the deep layer, the collecting tube gradually increases from the cortex to the medulla. Lower filtration rate of glomeruli in Camelus bactrianus lead to full water reabsorption from raw urine (Rytand, 1938). At the same time, broader medulla and Longer loop in the kidney of Camelus bactrianus provide necessary structural basis for the formation of high osmotic pressure gradient. The structure of kidney in these two animals is consistent with their adaptation to terrestrial environment, ensuring that they can live without water 
sources for a long-time. This is in consistent with the research that animals living here have a range of regulatory mechanisms, such as urinary concentration, reduced evaporation and loss of water, and production of metabolic water, to facilitate the survival and maintenance of water balance in dry climates (Tirado et al., 2008).

Animals living in desert environments are faced with the problem of water utilization and conservation. In addition to structural adaptation, the way that water transfer is also essential for them. Aquaporins are water channels which can provide rapid and efficient transfer of large amounts of water molecules across the membrane. Thirteen AQPs have been identified so far in mammals. Different AQPs have specific tissue distribution and execute particular physiological function. An established osmotic gradient and the presence of AQP water channels in membranes of glands and epithelia together form the biological basis for facilitated fluid secretion. However, there is little knowledge about the involvement of these proteins in the urine concentrating mechanism in animals living in the desert. In other animals, AQP1 is a water-channel protein, constitutively and abundantly expressed on both the apical and basolateral domains of proximal tubular cells and the descending limb of Ansa nephroni (Henle's loop) cells (Takata et al., 2004) and multiple studies have underscored the critical role of AQP2 in several inherited and acquired water balance disorders (Starklint et al., 2005). In this work, our results show that both animals presented normal renal function with the help of AQPs. In this study, the expression of AQP1, AQP2 protein in the kidney of Phrynocephalus vlangalii, Camelus bactrianus were expressed in the epithelial cells and the combined tube, but the expression characteristics of different parts and different parts of the same species were different. AQP1 is an important protein in kidney with water reabsorption function, and AQP2 is an important functional protein in kidney for urine concentration. The high expression of these two proteins in Phrynocephalus vlangalii and Camelus bactrianus are the molecular biological evidence that it can adapt well to the harsh environment of extreme drought and water shortage. In agreement with anatomy reports, we propose that the excess of AQP1, 2 protein could be considered as an adaptive mechanism similar to other animals.

Kidney is an important tissue of urinary system, which has the function of maintaining water balance and internal environment stability. AQP1 and AQP2 are stimulated by factors such as adrenocortical hormones, potassium levels in the blood and high osmotic pressure conditions, which contribute to adaptive regulation in the long-term evolution. The reuptake of salt by the kidneys was once beneficial to the survival of the organism, so the genes that drive the absorption of salt by the kidneys were selected by natural selection. But when the environment changeness were far than the gene evolution, What used to be an advantage become actually harmful to the body. Rats fasted for 24 hours developed a reduction in their urinary concentrating capacity, since 24 hours of fasting increased urine volume, suppressed AQP2 in the collecting duct (Amlal et al., 2001). In the native kidney, renal tubular epithelial cells serve to reabsorb salt and water filtered by the glomerulus while allowing uremic toxins to concentrate in the urine. However, renal tubular epithelial cells that are removed from their in vivo tend to lose their transport capacity (Love et al., 2019) until an overexpression of NHE3 and AQP1(Wilson et al., 2019). Different AQP1 expression pattern was found in Polyuria groups, with no changes in AQP1 localization, suggesting that changes in AQP1 may be involved in the development of polyuria (Seyahian et al.). Other than in the kidney, AQP1- knockout perturbed tumor angiogenesis and led to reduced brain injury upon trauma. On the cellular level, AQP1- knockout caused neuroinflammation, aberrant cell proliferation and migration, and macrophages infiltration (Hua et al., 2019). Hereditary mutations in the AQP2 gene are responsible for approximately $10 \%$ of congenital nephrogenic diabetes insipidus (NDI) cases (Bockenhauer \& Bichet, 2015). Currently, 65 different mutations of the AQP2 gene have been reported to cause NDI (Milano et al., 2017). The majority of these mutations are of recessive inheritance and generally caused by amino-acid substitutions in the transmembrane domains or connecting loops of the monomer resulting in AQP2 misfolding and intracellular retention (Moeller et al., 2013). In rare cases NDI can also be autosomal dominant. These cases are caused by AQP2 mutations residing in the carboxyl terminus of AQP2 resulting in misrouting of the protein to the Golgi complex, late endosomes or lysosomes (Marr et al., 2002).

In conclusion, increased knowledge about the difference in renal anatomy and AQPs expression in these two organisms partly reveal that structure adaptation and AQPs work together to overcome the water shortage.

AN, F. \& ZHU, S. La distribución y función de la acuaporina 1 y 2 a lo largo del riñón en diferentes especies. Int. J. Morphol., 39(3):890-895, 2021.

RESUMEN: El metabolismo del agua en los riñones es fundamental para los organismos que viven en ambientes áridos. En este estudio, se estudió la estructura renal y la expresión de AQP1 y AQP2 en Phrynocephalus vlangalii y Camelus bactrianus. Se encontró que Phrynocephalus vlangalii tiene menos corpúsculos renales. pero desarrolló túbulos renales, y AQP1 y AQP2 se expresaron principalmente en los túbulos renales. Camelus 
bactrianus tiene un glomérulo de gran diámetro, una membrana bulbar gruesa y un tracto urinario largo y denso. AQP1 se expresó en gran medida en el túbulo contorneado proximal, el túbulo recto proximal y el Ansa nephroni o asa nefrónica (asa de Henle), y AQP2 también se expresó en gran medida en el túbulo colector y el túbulo contorneado distal. A largo plazo, en la adaptación evolutiva la estructura morfológica del riñón animal es coherente con su entorno. Además de la adaptación estructural y funcional, la acuaporina también es parte de la adaptación al entorno de escasez de agua y puede desempeñar un papel clave.

PALABRAS CLAVE: Aquaporin1; Aquaporina2; Riñón; Phrynocephalus vlangalii; Camelus bactrianus

\section{REFERENCES}

Amlal, H.; Chen, Q.; Habo, K.; Wang, Z. \& Soleimani, M. Fasting down regulates renal water channel AQP2 and causes polyuria. Am. J. Physiol. Renal Physiol., 280(3):F513-23, 2001.

Bockenhauer, D. \& Bichet, D. G. Pathophysiology, diagnosis and management of nephrogenic diabetes insipidus. Nature Rev. Nephrol., 11(10):576-88, 2015.

Hua, Y.; Ying, X.; Qian, Y.; Liu, H.; Lan, Y.; Xie, A. \& Zhu, X. Physiological and pathological impact of AQP1 knockout in mice. Biosci. Rep., 39(5):BSR20182303, 2019.

Ishibashi, K.; Tanaka, Y. \& Morishita, Y. The role of mammalian superaquaporins inside the cell. Biochim. Biophys. Acta., 1840(5):150712, 2014.

Jin, Y. T. \& Liu, N. F. Altitudinal variation in reproductive strategy of the toad-headed lizard, Phrynocephalus vlangalii in North Tibet Plateau (Qinghai). Amphibia-Reptilia, 28(4):509-15, 2007.

Kortenoeven, M. L. A.; Pedersen, N. B.; Miller, R. L.; Rojek, A. \& Fenton, R. A. Genetic ablation of aquaporin-2 in the mouse connecting tubules results in defective renal water handling. J. Physiol., 591(8):2205-19, 2013.

Lanaspa, M. A.; Andres-Hernando, A.; Li, N.; Rivard, C. J.; Cicerchi, C.; Roncal-Jimenez, C.; Schrier, R. W. \& Berl, T. The expression of aquaporin-1 in the medulla of the kidney is dependent on the transcription factor associated with hypertonicity, TonEBP. J. Biol. Chem., 285(41):31694-703, 2010.

Love, H. D.; Ao, M.; Jorgensen, S.; Swearingen, L.; Ferrell, N.; Evans, R. C.; Gewin, L.; Harris, R. C.; Zent, R.; Roy, S.; et al. Substrate elasticity governs differentiation of renal tubule cells in prolonged culture. Tissue Eng. Part A, 25(13-14):1013-22, 2019.

Marr, N.; Bichet, D. G.; Lonergan, M.; Arthus, M. F.: Jeck, N.; Seyberth, H. W.; Rosenthal, W.; van Os, C. H.; Oksche, A. \& Deen, P. M. T. Heteroligomerization of an Aquaporin-2 mutant with wild-type Aquaporin-2 and their misrouting to late endosomes/lysosomes explains dominant nephrogenic diabetes insipidus. Hum. Mol. Genet., 11(7):77989, 2002.

Mbassa, G. K. Mammalian renal modifications in dry environments. Vet. Res. Commun., 12(1):1-18, 1988.

Milano, S.; Carmosino, M.; Gerbino, A.; Svelto, M. \& Procino, G. Hereditary nephrogenic diabetes insipidus: pathophysiology and possible treatment. An update. Int. J. Mol. Sci., 18(11):2385,2017.

Moeller, H. B.; Rittig, S. \& Fenton, R. A. Nephrogenic diabetes insipidus: essential insights into the molecular background and potential therapies for treatment. Endocr. Rev., 34(2):278-301, 2013.

Nielsen, S.; Frokiaer, J.; Marples, D.; Kwon, T. H. \& Knepper, M. A. Aquaporins in the kidney: From molecules to medicine. Physiol. Rev., 82(1):205-44, 2002
Nielsen, S.; Kwon, T. H.; Frokiaer, J. \& Agre, P. Regulation and dysregulation of aquaporins in water balance disorders. J. Intern. Med., 261(1):53-64, 2007.

Romagnani, P.; Lasagni, L. \& Remuzzi, G. Renal progenitors: an evolutionary conserved strategy for kidney regeneration. Nat. Rev. Nephrol., 9(3):137-46, 2013.

Rytand, D. A. The number and size of mammalian glomeruli as related to kidney and to body weight, with methods for their enumeration and measurement. Am. J. Anat., 62(4):507-20,1938.

Seyahian, E. A.; Cacciagiu, L.; Damiano, A. E. \& Zotta, E. AQP1 expression in the proximal tubule of diabetic rat kidney. Heliyon, 6(1):e03192, 2020.

Solomon, S. E. The morphology of the kidney of the green turtle (Chelonia mydas L.). J. Anat., 140(Pt. 3):355-69, 1985.

Starklint, J.; Bech, J. N. \& Pedersen, E. B. Down-regulation of urinary AQP2 and unaffected response to hypertonic saline after 24 hours of fasting in humans. Kidney Int., 67(3):1010-8, 2005.

Takata, K.; Matsuzaki, T. \& Tajika, Y. Aquaporins: water channel proteins of the cell membrane. Prog. Histochem. Cytochem., 39(1):1-83, 2004.

The Bactrian Camels Genome Sequencing and Analysis Consortium. Genome sequences of wild and domestic bactrian camels. Nat. Commun., 3(1):1-8, 2012.

Tirado, C.; Cortes, A. \& Bozinovic, F. Water balance in two south american phyllotis desert rodents, $p$. xanthopygus rupestris and p. darwini darwini. J. Arid Environ., 72(5):664-70, 2008.

Westrick, K. Y.; Serack, B.; Dantzler, W. H. \& Pannabecker, T. L. Axial compartmentation of descending and ascending thin limbs of Henle's loops. Am. J. Physiol. Renal Physiol., 304(3):F308-16, 2012.

Wilson, M. H.; Veach, R. A.; Luo, W.; Welch, R. C.; Roy, S. \& Fissell, W. H. Genome engineering renal epithelial cells for enhanced volume transport function. Cell. and Mol. Bioeng., 13(1):17-26, 2019.

\section{Corresponding author: \\ Fengli An \\ School of Pharmacy \\ Lanzhou university \\ Gansu \\ CHINA}

E-mail: afl_1981@163.com

Received: 30-11-2020

Accepted: 18-02-2021 